\title{
Patient safety culture according to nursing professionals of an accredited hospital
}

\author{
Cultura de segurança do paciente segundo profissionais \\ de enfermagem de um hospital acreditado
}

Cultura de seguridad del paciente según profesionales de enfermería de un hospital acreditado

How to cite this article: Melo E, Balsanelli AP, Neves VR, Bohomol E. Patient safety culture according to nursing professionals of an accredited hospital. Rev Gaúcha Enferm. 2020;41:e20190288. doi: https://doi. org/10.1590/1983-1447.2020.20190288 aniversidade Federal de São Paulo (UNIFESP) Escola Paulista de Enfermagem, Departamento de Administração em Serviços de Saúde Enfermagem, São Paulo, São Paulo, Brasil.
ABSTRACT

Objective: To evaluate the perception of the nursing team regarding the patient safety culture of an accredited hospital and to identify the differences between shifts, professional category and units.

Method: Cross-sectional study, conducted in a private hospital in the city of São Paulo, SP, Brazil, with application of the Survey on Patient Safety Culture Hospital to 497 nursing professionals. Descriptive analysis, instrument consistency and generalized linear mixed model were performed.

Results: The organizational learning and continuous improvement dimension was considered a strong area (77\%) and the personal adequacy (47\%), shift / shift change and transfer (47\%) and non-punitive response to errors (25\%) dimensions were considered. fragile. Differences in perception were found between the professional categories in two dimensions; between shifts in six and between units in seven dimensions.

Conclusion: The nursing team identified weaknesses in the patient safety culture in the hospital, with the need to standardize the improvement processes.

Keywords: Patient safety. Organizational culture. Health services research. Hospitals. Nursing.

\section{RESUMO}

Objetivo: Avaliar a percepção da equipe de enfermagem quanto à cultura de segurança do paciente de um hospital acreditado e identificar as diferenças entre turnos, categoria profissional e unidades.

Método: Estudo transversal, realizado num hospital privado, na cidade de São Paulo, SP, Brasil, com aplicação do Hospital Survey on Patient Safety Culture a 497 profissionais de enfermagem. Realizou-se análise descritiva, consistência do instrumento e modelo misto linear generalizado.

Resultados: A dimensão aprendizado organizacional e melhoria contínua foi considerada área forte (77\%) e as dimensões adequação pessoal (47\%), passagem de plantão/turno e transferência (47\%) e resposta não punitiva aos erros (25\%) foram consideradas frágeis. Foram encontradas diferenças de percepção entre as categorias profissionais em duas dimensões; entre os turnos em seis e entre os setores em sete dimensões.

Conclusão: A equipe de enfermagem identificou fragilidades na cultura de seguranç̧a do paciente no hospital, havendo necessidade de uniformizar os processos de melhoria.

Palavras-chave: Segurança do paciente. Cultura organizacional. Pesquisa sobre serviços de saúde. Hospitais. Enfermagem.

\section{RESUMEN}

Objetivo: Evaluar la percepción del equipo de enfermería con respecto a la cultura de seguridad del paciente de un hospital acreditado e identificar las diferencias entre turnos, categoría profesional y unidades.

Método: Estudio transversal, realizado en un hospital privado de la ciudad de São Paulo, SP, Brasil, con aplicación de la Encuesta sobre el Hospital de Cultura de Seguridad del Paciente a 497 profesionales de enfermería. Se realizó un análisis descriptivo, consistencia del instrumento y modelo mixto lineal generalizado

Resultados: La dimensión de aprendizaje organizacional y mejora continua se consideró un área fuerte (77\%) y se consideraron las dimensiones de adecuación personal (47\%), turno / turno y transferencia (47\%) y respuesta de error no punitiva (25\%) frágil. Se encontraron diferencias en la percepción entre las categorías profesionales en dos dimensiones; entre turnos en seis y entre sectores en siete dimensiones.

Conclusión: El equipo de enfermería identificó debilidades en la cultura de seguridad del paciente en el hospital, lo que requiere la estandarización de los procesos de mejora.

Palabras clave: Seguridad del paciente. Cultura organizacional. Investigación sobre servicios de salud. Hospitales. Enfermería. 


\section{口INTRODUCTION}

Organizations classified as high risk have regularly assessed their safety culture through the professionals' perceptions of the procedures and behaviors in their work environment, in order to point out the priorities in relation to safety in view of the organizational guidelines ${ }^{(1)}$.

In the global health scenario, international bodies, accrediting agencies and government policies have given importance to the assessment of the safety culture in institutions, as they consider the high risk area for the occurrence of adverse events ${ }^{(2)}$. Such movement indicates the need to first understand this culture in order to then identify areas in need of improvement, sensitize professionals about the importance of patient safety, evaluate quality programs and monitor institutional changes in order to improve patient care ${ }^{(1,3)}$.

The safety culture is the set of values, attitudes, skills and behaviors that determine commitment to health and safety management, replacing guilt and punishment with the opportunity to learn from failures and improve health care $^{(3)}$.

The patient safety culture can be studied using several methods and there are some questionnaires created and validated to analyze it. One of the most used worldwide is the Hospital Survey on Patient Safety Culture (HSOPSC), developed by the US Agency for Healthcare Research and Quality $(\mathrm{AHRQ})^{(3-4)}$.

Studies about the patient safety culture present different views and their results sometimes reflect the perception of a professional category ${ }^{(5)}$; sometimes from two or more professions ${ }^{(6)}$; sometimes from an organization, whether public, private or educational(7-8); or even specialized units ${ }^{(9)}$.

In order to increase awareness of patient safety culture, assessments should be made at periodic intervals, making it possible to compare the perception between different professional categories and work units in order to determine the areas that need the most attention from leaders to implement action plans to promote it $\mathrm{it}^{(4)}$.

Health organizations looking for strategies to improve the quality and safety of their services by implementing accreditation programs refer to a differential in improving internal processes, better development of the safety culture, strengthening of the institutional image and competitive differentiation ${ }^{(4,10)}$.

Accreditation allows to develop actions aimed at improving quality, making patient safety part of the corporate culture and the nursing team has a great influence on the success of its implementation ${ }^{(4)}$. This methodology aims to promote, in an equitable way, safe care processes and in adequate working conditions, taking into account the continuity of assistance in the different work shifts of professionals in view of the characteristics of the units, regardless of the levels of complexity and severity of the assisted patients ${ }^{(10)}$.

Since there are few studies that aim to understand how the perception of the patient safety culture is in institutions with quality programs in place, the question is: What is the perception of the nursing team about patient safety in an accredited institution? In order to answer the question presented, this study aimed to assess the perception of the nursing team regarding the patient safety culture of an accredited hospital and to identify the differences between shifts, professional category and units.

\section{METHOD}

This is a cross-sectional study, with a quantitative approach, carried out in a private non-profit hospital, with assistance to patients with supplementary and private health care, in the city of São Paulo, SP, Brazil. The institution started a quality and safety program in 2007 and during this period it received national accreditation certifications (National Accreditation Organization level III in 2008) and international (Health Standards Organization in 2011 and Joint Commission International in 2012), being periodically recertified. The hospital had 310 inpatient beds, distributed in several care sectors.

It has been considered as criteria inclusion: having a job with the institution and carrying out care activities with direct contact with the patient. The exclusion criteria were: employees who were on vacation, time off or on leave, and nurses who held leadership positions, such as department heads, coordinators and supervisors.

A non-probabilistic sample was used for the convenience of nursing professionals allocated in the sectors of Adult and Pediatric Inpatient Units (IU); Adult Intensive Care Unit (AICU); Child Intensive Care Unit (CICU); Surgical Center (SC); Adult Emergency Room (AER); Children's Emergency Room (CER); and Oncology and Bone Marrow Transplant Unit (ONCO/BMT).

The instrument for data collection was HSOPSC, designed by researchers Sorra and Neiva ${ }^{(3)}$ and validated for the Brazilian reality by Reis ${ }^{(11)}$. The HSOPSC was developed to assess the perception of staff working in hospitals, in relation to the different characteristics of the safety culture and is one of the most used worldwide to measure the patient safety culture ${ }^{(11)}$. It contains 42 items related to the patient safety culture and that measure 12 dimensions, namely: 1. Support from hospital management for patient 
safety; 2 . Teamwork between units; 3 . Shift change/shift and internal transfers; 4. Supervisor/manager expectations and actions promoting safety; 5 . Organizational learning and continuous improvement; 6 . Teamwork within the units; 7. Communication opening; 8 . Feedback and communication about errors; 9 . Non-punitive response to errors; 10 . Staff adequacy; 11 . General perception of patient safety; and 12. Frequency of reported events. In the instrument, there is an item in which the participants attribute a degree of patient safety and another, in which they report the number of adverse events reported in the last 12 months.

To calculate the dimensions of the questionnaire, each item of the HSOPSC was considered in the form of the Likert scale in five answer options, being: 1 for totally/never disagree; 2 for disagree/rarely; 3 for not agree or disagree/ sometimes; 4 for agree/almost always and, 5 for totally agree/always inverting the order of the score in the reverse questions, that is, those in which the participant disagrees with the item formulated negatively, but will be expressing his opinion in a positive way. The dimensions were then calculated by the average of the items that comprised it, consequently varying its score from 1 to 5 points. The answers were grouped into positive (totally agree/agree or always/almost always), neutral (neither agree nor disagree or sometimes), and negative (strongly disagree/disagree or never/rarely) ${ }^{(3)}$.

Additionally, the composition of the percentage of positive responses in the 12 dimensions followed the formula recommended by $A H R Q$, which was calculated using the number of positive answers to items in the dimension, divided by the total number of valid answers (positive, neutral and negative) to the items in the dimension. The percentage of positive answers represents an assertive reaction in relation to the patient's safety culture and allows the assessment of strong areas (scores above 75\%), neutral (scores between 50 and $75 \%$ ) and fragile (scores below 50\%) of the safety culture ${ }^{(3)}$. The data were described and analyzed by dimension.

The internal consistency of the HSOPSC dimensions was assessed by Cronbach's Alpha coefficient and the level considered satisfactory was $\geq 0.60^{(3,12)}$.

The comparison between the total of positive answers for each one of the 12 dimensions was tested by a generalized linear mixed model considering binomial distribution (with logistical connection) for agreement with the domain items. The mixed model allows considering the dependence between the answers of the same individual to the questions that make up the dimension. The analysis used a significance level of $5 \%(p<0.05)$ and were performed using the software R 3.2.3.
The instrument was made available online to all employees of the institution, using the Interact ${ }^{\circledR}$ software, from July 12 to 24,2016 , during the institutional research on patient safety culture to be completed on a day and time as the convenience of professionals. For the nursing team, the Free and Informed Consent Term was added, which was approved by the institution's Quality Office, requesting authorization for the use of the data in the research. At the end of the institutional research period, the data referring to nursing professionals were delivered to researchers in a Microsoft Excel 2010 spreadsheet for data analysis.

This study followed the precepts of Resolution 466/12 of the National Health Council and was approved by the Research Ethics Committee of the Universidade Federal de São Paulo and the participating Institution according to statement No. 655.946.

\section{Q RESULTS}

From 861 nursing professionals, 497 (57.7\%) participated the researh. The professionals were mostly female and nursing technicians. It was verified that $53.9 \%$ had secondary education, $62.3 \%$ worked in the sector between 1 and 5 years; $34.8 \%$ had between 1 and 5 years since graduation, with equivalence in the distribution between work shifts. (Table 1).

In this study, the Cronbach's Alpha values for the dimensions ranged between 0.45 and 0.91 in the 12 dimensions studied, with six of them having an index below 0.60. A strong area was found "organizational learning and continuous improvement" with a score of $77 \%$ and an average of $3.8( \pm 0.6)$ representing moderate concordance to the items evaluated. Eight dimensions showed positive answers between 50 and $75 \%$, considered as neutral areas, with averages between 3.3 and 4 points, which indicate neutral scores until moderate concordance with the evaluated items. Three dimensions were considered fragile (positive answers with scores below 50\%) with an average between 2.6 and 3.2 and the dimension "non-punitive response to errors", with the lowest of the scores (25\% and average of 2.6 points) (Table 2).

Regarding the perceived degree of patient safety, 79 (17.8\%) professionals rated the concept "excellent", 268 (60\%) "very good", while 84 (18.9\%) indicated to the concept"regular", 10 (2.2\%) for "bad" and 5 (1.1\%) professionals rated it as "very bad".

Regarding the number of notifications 232 (51.4\%) professionals reported not having made any notifications in the last 12 months, 110 (24.4\%) made one to two notifications, 72 (16.0\%) from 3 to 5 notifications and 37 (9.2\%) more than six notifications in the same period. 
Table 1 - Participants characterization regarding gender, professional category, education, shift, time in sector and formation time ( $n=497)$. São Paulo/SP, Brazil. 2016

\section{Variables}

\section{Gender}

Female

Male

\section{Professional category}

Nursing assistant

Nursing technician

\section{Education}

High school

Higher education

Specialization

Master's degree

\section{Shift}

Morning

Afternoon

Night

\section{Time in sector}

Less than 1 year

1 to 5 years

6 to 10 years

11 to 15 years

16 years or more

\section{Formation time}

Less than 1 year

1 to 5 years

6 to 10 years

11 to 15 years 
Table 2 - Positive answers presentation, with average and standard deviation and reliability by Cronbach's Alpha for each dimension of the Hospital Survey on Patient Safety Culture instrument $(n=497)$. São Paulo / SP, Brazil. 2016

\begin{tabular}{|c|c|c|c|}
\hline Dimension & $\begin{array}{l}\text { Average } \pm \\
\text { standard } \\
\text { deviation }\end{array}$ & $\begin{array}{c}\text { Positive } \\
\text { answers } \\
\%\end{array}$ & $\begin{array}{c}\text { Cronbach's } \\
\text { Alpha }\end{array}$ \\
\hline Supervisor/manager expectations and actions promoting safety & $3.5 \pm 0.9$ & 61 & 0.80 \\
\hline Organizational learning and continuous improvement & $3.8 \pm 0.6$ & 77 & 0.57 \\
\hline Teamwork within the units & $3.5 \pm 0.7$ & 63 & 0.72 \\
\hline Communication opening & $3.4 \pm 0.9$ & 50 & 0.62 \\
\hline Feedback and communication about errors & $3.9 \pm 0.9$ & 64 & 0.67 \\
\hline Non-punitive response to errors & $2.6 \pm 0.7$ & 25 & 0.45 \\
\hline Staff adequacy & $3.1 \pm 0.6$ & 47 & 0.45 \\
\hline Hospital management support for patient safety & $3.7 \pm 0.6$ & 69 & 0.59 \\
\hline Teamwork between units & $3.3 \pm 0.6$ & 52 & 0.56 \\
\hline Shift change/shift and internal transfers & $3.2 \pm 0.8$ & 47 & 0.78 \\
\hline General perception of patient safety & $3.4 \pm 0.6$ & 60 & 0.51 \\
\hline Frequency of reported events & $4.0 \pm 1.0$ & 68 & 0.91 \\
\hline
\end{tabular}

Source: Research data, 2016.

When comparing the perceptions between nursing assistants and nursing technicians (Table 3), the dimensions that showed significant differences were"supervisor/manager expectations and actions promoting safety" $(p<0.001)$ and "shift change/shift and internal transfers" ( $p=0.043)$.

As for work shifts, Table 4 shows statistically significant differences in six dimensions:"supervisor/manager expectations and actions promoting safety" $(p=0.021)$,"organizational learning and continuous improvement" $(p=0.049)$,"teamwork within the units" $(p<0.001)$, "feedback and communication about errors" $(p=0.031)$, "teamwork between units" $(p=0.038)$ and "general perception of patient safety" $(p<0.001)$.

The analysis of the professionals positive answers in the work sectors studied pointed out a significant difference in seven dimensions:"supervisor/manager expectations and actions promoting safety" $(p<0.001)$, "teamwork within the units" $(p<0.001)$, "communication opening" $(p=0.007)$, "feedback and communication about errors" ( $p=0.001)$, "non-punitive response to errors" $(p=0.001)$, "staff adequacy" $(p<0.001)$, and "teamwork between units" ( $p=0.001$ ) (Table 5).

\section{DISCUSSION}

The participants are nursing technicians, many with higher education level, with less than five years in the sector. The results show differences when compared to a brazilian study carried out in public sector hospitals, which presents an expressive participation of nursing assistants with longer experience in the institution, due to the employment relationship being statutory ${ }^{(7)}$.

The HSOPSC survey, used in different countries, has also been applied in brazilian institutions to know about the 
Melo E, Balsanelli AP, Neves VR, Bohomol E

Table 3 - Positive answers percentage for each dimension of the Hospital Survey on Patient Safety Culture instrument according to professional category $(n=497)$. São Paulo/SP, Brazil. 2016

\begin{tabular}{|c|c|c|c|}
\hline Dimension & $\begin{array}{c}\text { Nursing } \\
\text { assistant } \\
(n=184)\end{array}$ & $\begin{array}{c}\text { Nursing } \\
\text { technician } \\
(n=313)\end{array}$ & p * \\
\hline Supervisor/manager expectations and actions promoting safety & 63 & 60 & $<0.001$ \\
\hline Organizational learning and continuous improvement & 79 & 77 & 0.364 \\
\hline Teamwork within the units & 63 & 63 & 0.993 \\
\hline Communication opening & 51 & 49 & 0.518 \\
\hline Feedback and communication about errors & 67 & 62 & 0.077 \\
\hline Non-punitive response to errors & 27 & 24 & 0.175 \\
\hline Staff adequacy & 47 & 48 & 0.656 \\
\hline Hospital management support for patient safety & 68 & 70 & 0.537 \\
\hline Teamwork between units & 52 & 52 & 0.864 \\
\hline Shift change/shift and internal transfers & 43 & 50 & 0.043 \\
\hline General perception of patient safety & 59 & 61 & 0.616 \\
\hline Frequency of reported events & 73 & 65 & 0.384 \\
\hline
\end{tabular}

Source: Research data, 2016.

*Variance analysis for a generalized linear mixed model for binomial distribution (with logistical connection) for concordance with domain items. Statistically significant $p<0.05$.

Table 4 - Positive answers percentage for each dimension of the Hospital Survey on Patient Safety Culture instrument according to shift $(n=497)$. São Paulo/SP, Brazil. 2016

\begin{tabular}{lcccc} 
Dimension & $\begin{array}{c}\text { Morning } \\
(\mathbf{n = 1 8 0 )}\end{array}$ & $\begin{array}{c}\text { Afternoon } \\
(\mathbf{n = 1 5 8})\end{array}$ & $\begin{array}{c}\text { Night } \\
\text { (n=159) }\end{array}$ & $\mathbf{p}^{*}$ \\
\hline Supervisor/manager expectations and actions promoting safety & 64 & 65 & 55 & 0.021 \\
Organizational learning and continuous improvement & 82 & 77 & 74 & 0.049 \\
Teamwork within the units & 60 & 67 & 64 & $<0.001$ \\
Communication opening & 52 & 52 & 45 & 0.122 \\
Feedback and communication about errors & 67 & 66 & 58 & 0.031 \\
Non-punitive response to errors & 26 & 27 & 21 & 0.142 \\
Staff adequacy & 46 & 47 & 49 & 0.612 \\
Hospital management support for patient safety & 70 & 73 & 66 & 0.139 \\
Teamwork between units & 54 & 57 & 48 & 0.038 \\
Shift change/shift and internal transfers & 45 & 51 & 47 & 0.4 \\
General perception of patient safety & 63 & 64 & 53 & $<0.001$ \\
Frequency of reported events & 70 & 66 & 67 & 0.89 \\
\hline
\end{tabular}

Source: Research data, 2016

* Variance analysis for a generalized linear mixed model for binomial distribution (with logistical connection) for concordance with domain items. Statistically significant $p<0.05$ 
Table 5 - Positive answers percentage for each dimension of the Hospital Survey on Patient Safety Culture instrument according to sector ( $n=497)$. São Paulo/SP, Brazil. 2016

\begin{tabular}{|c|c|c|c|c|c|c|c|c|}
\hline Dimension & $\underset{(n=37)}{S C}$ & $\begin{array}{l}\text { ONCO } \\
\text { BMT } \\
(n=18)\end{array}$ & $\underset{(n=62)}{A E R}$ & $\begin{array}{c}\text { CER } \\
(n=17)\end{array}$ & $\underset{(n=185)}{I U}$ & $\underset{(n=24)}{C I C U}$ & $\underset{(n=154)}{A I C U}$ & p* \\
\hline $\begin{array}{l}\text { Supervisor/manager } \\
\text { expectations and actions } \\
\text { promoting safety }\end{array}$ & 55 & 82 & 46 & 90 & 66 & 76 & 56 & $<0.001$ \\
\hline $\begin{array}{l}\text { Organizational learning and } \\
\text { continuous improvement }\end{array}$ & 74 & 85 & 71 & 86 & 81 & 82 & 74 & 0.064 \\
\hline Teamwork within the units & 44 & 76 & 71 & 84 & 65 & 74 & 56 & $<0.001$ \\
\hline Communication opening & 44 & 67 & 45 & 73 & 51 & 47 & 46 & 0.007 \\
\hline $\begin{array}{l}\text { Feedback and } \\
\text { communication } \\
\text { about errors }\end{array}$ & 45 & 82 & 57 & 82 & 65 & 69 & 64 & 0.001 \\
\hline $\begin{array}{l}\text { Non-punitive response } \\
\text { to errors }\end{array}$ & 29 & 24 & 22 & 49 & 24 & 42 & 22 & 0.001 \\
\hline Staff adequacy & 39 & 53 & 33 & 46 & 44 & 65 & 56 & $<0.001$ \\
\hline $\begin{array}{l}\text { Hospital management } \\
\text { support for patient safety }\end{array}$ & 69 & 78 & 66 & 77 & 71 & 72 & 66 & 0.563 \\
\hline Teamwork between units & 47 & 71 & 52 & 63 & 56 & 53 & 44 & 0.001 \\
\hline $\begin{array}{l}\text { Shift change/shift and } \\
\text { internal transfers }\end{array}$ & 48 & 56 & 46 & 54 & 49 & 54 & 42 & 0.41 \\
\hline $\begin{array}{l}\text { General perception of } \\
\text { patient safety }\end{array}$ & 63 & 61 & 56 & 78 & 58 & 57 & 62 & 0.084 \\
\hline $\begin{array}{l}\text { Frequency of } \\
\text { reported events }\end{array}$ & 63 & 80 & 57 & 92 & 63 & 79 & 75 & 0.09 \\
\hline
\end{tabular}

Source: Research data, 2016

SC = Surgical Center; ONCO/BMT = Oncology and Bone Marrow Transplant Unit; AER = Adult Emergency Room; CER = Children's Emergency Room; IU = Adult and Pediatric Inpatient Units; CICU = Child Intensive Care Unit; AICU = Adult Intensive Care Unit;

* Variance analysis for a generalized linear mixed model for binomial distribution (with logistical connection) for concordance with domain items. Statistically significant $p<0.05$. 
patient safety culture. The coefficients of this research ranged from 0.45 to 0.91 and the dimensions "non-punitive response to erros" and "staff adequacy" were those with the lowest reliability coefficient (0.45). Studies on patient safety culture also show variability with values between 0.63 to $0.84^{(3)} ; 0.52$ to $0.91^{(11)}$; or 0.40 to $0.88^{(13)}$. In addition, the lowest values in relation to the two dimensions were also found in national $(0.35 \text { and } 0.20)^{(11)}$ and international studies $(0.55 \text { e } 0.54)^{(14)}$.

The reliability of an instrument depends on numerous factors, such as: its function, number of items, population in which it is applied, context and circumstances found and method of administration, among others, and, therefore, variations are expected ${ }^{(12)}$. Regarding the survey developed by $A H R Q$, the findings allow comparisons with other researchers, with no reports of restructuring or question exclusions being found even with the variation in reliability tests. ${ }^{(13)}$. As the Cronbach's Alpha must be interpreted in the light of the measurement characteristics and associated with the study population, the values found may reflect an insufficient understanding of the nursing team regarding the researched dimensions. Therefore, it is recommended that the instrument be used with different samples so that it can provide confirmation of its validity and reliability ${ }^{(11)}$.

The area considered strong by the participants was "organizational learning and continuous improvement", unlike a study carried out in a hospital accredited in Turkey or in a Brazilian university hospital, in which the dimension found was configured in a neutral area (63\% and $58 \%$ respectively) $)^{(4,13)}$.

Organizational learning implies continually reviewing its processes and developing leadership committed to patient safety, as it provides ongoing support for efforts and improvement initiatives at different hierarchical levels $s^{(15)}$. Corroborates the statement that the dimensions"supervisor/ manager expectations and actions promoting safety" and "hospital management support for patient safety" obtained positive response values above $60 \%$, different from Brazilian and European studies that point to the latter dimension as fragile, with rates of 33 and $35 \%(13,16)$.

In contrast, the research showed that the most fragile dimension is the "non-punitive response to errors", even with significant differences when analyzed from the perspective of the different sectors studied. This data confirms national (with positive responses of $18 \%$ and $36 \%)^{(13,17)}$ and international studies (17 e 33\%) (16,18) $^{(1)}$ and indicates that it is the one with the lowest index of positive responses representing a weakness within health institutions around the world.

Although the institution studied has its accreditation programs, defined as a systematic, periodic, voluntary strategy, based on determined quality standards, it, in itself, did not confer a greater positive percentage for the dimension "non-punitive response to errors", which allows affirm that there is still an accusatory culture, needing to develop a non-punitive environment to promote a safety culture ${ }^{(14)}$. A similar data was found in a study conducted in an accredited hospital in Turkey, which presented 33\% of positive responses in this dimension ${ }^{(4)}$ and in an accredited teaching hospital in Portugal, with 28\% ${ }^{(19)}$, bringing the challenge for hospital leadership with quality programs to look closely at this dimension.

The dimension "staff adequacy" was also considered fragile, with significant differences between sectors, and this result corresponds to studies carried out in Brazil in state, federal and university hospitals (with positive responses in the proportion of 30,43 and $33 \%$, respectively) $)^{(13,17)}$ or in accredited services $(22 \% \text { e } 43 \%)^{(4,19)}$

Staff sizing is a critical issue for managers, due to spending on people, as it is for those who work in direct care for patients with a deficient scale and a higher risk of adverse events. Even today, the number of personnel is not sufficient for the care demands in many health institutions, including critical areas, sometimes requiring more hours of work to promote patient care ${ }^{(19)}$.

The dimension "shift change/shift and internal transfers" was assessed as fragile and presented significant differences between professional categories, work shifts and sectors. The general indexes of positive responses are equivalent to those of national and international studies ${ }^{(13,18)}$, however, they differ from a study carried out in a private Brazilian hospital (proportion of positive responses of $60 \%)^{(17)}$ and in accredited hospitals $(66 \text { a } 70 \%)^{(4,19)}$, confirming the need to review the communication processes.

The quality degree perceived by the participants was found between the concept "excellent" and "very good" equivalent to an international study $(75 \%)^{(14)}$ and different from a national study in which $51 \%$ participants perceive quality as "regular"(13).

As for the number of participants who said they did not report adverse events in the last 12 months, the findings are similar to a national study $(53 \%)^{(13)}$ but are lower when compared to a study in an accredited hospital abroad (80.4\%) (14), pointing to an underreporting of events, quite common in hospital institutions.

The research analyzed the team's perceptions regarding the patient's safety in relation to their work period and identified significant differences in several dimensions, giving to nighttime shift professionals lower rates of positive responses. These results suggest an analysis for working conditions in this period of work, whether due to the workload, characteristics of the units, complexity and severity of patients, 
turnover of professionals, distance from management, among others. The importance of leadership in applying strategies aimed at professionals working in this shift is highlighted, in order to value their work, reduce stress, develop their potential, promote satisfaction and involve workers in aspects of patient safety ${ }^{(20)}$.

The perceptions of the professionals allocated to the different sectors of work were studied and the findings showed significant differences in seven dimensions, which indicates the need to verify working conditions to promote continuity of care in a safe manner, regardless the characteristics of the units, levels of complexity and severity of assisted patients ${ }^{(5)}$.

It is highlighted that the SC professionals evaluated seven dimensions with lower positive response rates, characterizing them as fragile. A study carried out in Turkey analyzed the perception of professionals from four hospitals and those who worked in SC perceived, as fragile, ten dimensions differently from the ICU professionals who identified four ${ }^{(14)}$. As it is an environment that can trigger conflicts, inappropriate and arrogant behaviors between teams or inadequate working conditions, knowing the safety culture in this scenario is an essential aspect to effect improvements.

\section{CONCLUSION}

The study allowed to know the perception of nurses and nursing technicians who work in the different sectors and work shifts in a hospital with accreditation certificates, about the patient safety culture.

The evaluation of the dimensions of the safety culture by the Hospital Survey on Patient Safety Culture presented a dimension considered as a strong area"organizational learning and continuous improvement", eight dimensions as neutral areas and three dimensions were considered fragile being "non-punitive response to errors" with the lowest of the scores.

There are differences in perception about the patient safety culture between the professional categories in two dimensions; between work shifts in six dimensions and between sectors in seven dimensions.

The limitations of the research refer to the low internal consistency in six dimensions, demonstrating fragility in the reliability of the professionals' answers, which can be interpreted as an insufficient understanding of the dimensions by the researched team; and also because the research was carried out in a single institution and its results do not allow generalizations, which imposes new studies on this theme. However, it contributes to assistance and teaching in the perspective of identifying which are the points of improvement that need to be addressed to increase the care quality and, consequently, the patient safety culture.

\section{REFERENCES}

1. Alsalem G, Bowie P, Morrison J. Assessing safety climate in acute hospital settings: a systematic review of the adequacy of the psychometric properties of survey measurement tools. BMC Health Serv Res. 2018;18:353. doi: https://doi. org/10.1186/s12913-018-3167-x

2. Capucho HC, Cassiani SHB. The need to establish a national patient safety program in Brazil. Rev Saúde Pública 2013;47(4):791-8. doi: https://doi.org/ 10.1590/S0034-8910.2013047004402

3. Sorra J, Gray L, Streagle S, et al. AHRQ Hospital Survey on Patient Safety Culture: User's guide. Rockville, MD: Agency for Healthcare Research and Quality; 2016 [cited 2019 Apr 30]. AHRQ Publication No. 15-0049-EF (Replaces 040041). Available from: https:/www.ahrq.gov/sites/default/files/wysiwyg/ professionals/quality-patient-safety/patientsafetyculture/hospital/userguide/ hospcult.pdf

4. Gözlü K, Kaya S. Patient safety culture as perceived by nurses in a Joint Commission International Accredited Hospital in Turkey and its comparison with Agency for Healthcare Research and Quality Data. Patient Saf Qual Improv. 2016 [cited 2019 July 10];4(4):441-9. Available from: http://psj.mums.ac.ir/ article_7640_9f9dd2489fbe1d50566a94452298fccc.pdf

5. Silva-Batalha EMS, Melleiro MM. Patient safety culture in a teaching hospital: differences in perception existing in the different scenarios of this institution. Texto Contexto Enferm. 2015;24(2):432-41. doi: https://doi. org/10.1590/0104-07072015000192014

6. Santiago THR, Turrini RNT. Organizational culture and climate for patient safety in Intensive Care Units. Rev Esc Enferm USP. 2015;49(esp):123-30. doi: https://doi.org/10.1590/S0080-623420150000700018

7. Carvalho REFL, Arruda LP, Nascimento NKP, Sampaio RL, Cavalcante MLSN, Costa ACP. Assessment of the culture of safety in public hospitals in Brazil. Rev Latino-Am Enfermagem. 2017;25:e2849. doi: https://doi.org/10.1590/ 1518-8345.1600.2849

8. Carvalho PA, Göttems LBD, Pires MRGM, Oliveira MLC. Safety culture in the operating room of a public hospital in the perception of healthcare professionals. Rev Latino-Am Enfermagem. 2015;23(6):1041-8. doi: https:// doi.org/10.1590/0104-1169.0669.2647

9. Batista J, Cruz EDA, Alpendre FT, Paixão DPSS, Gaspari AP, Mauricio AB. Safety culture and communication about surgical errors from the perspective of the health team. Rev Gaúcha Enferm. 2019;40(esp):e20180192. doi: https://doi. org/10.1590/1983-1447.2019.20180192

10. Saut AM, Berssaneti FT, Moreno MC. Evaluating the impact of accreditation on Brazilian healthcare organizations: a quantitative study. Int I Qual Health Care. 2017;29(5):713-21. doi: https://doi.org/10.1093/intqhc/mzx094

11. Reis CT, Laguardia J, Vasconcelos AGG, Martins M. Reliability and validity of the Brazilian version of the Hospital Survey on Patient Safety Culture (HSOPSC): a pilot study. Cad Saúde Pública. 2016;32(11):e00115614. doi: https://doi. org/10.1590/0102-311x00115614

12. Souza AC, Alexandre NMC, Guirardell EB. Psychometric properties in instruments evaluation of reliability and validity. Epidemiol Serv Saúde. 2017;26(3):649-59, doi: https://doi.org/10.5123/S1679-49742017000300022

13. Galvão TF, Lopes MCC, Oliva CCC, Araújo MEA, Silva MT. Patient safety culture in a university hospital. Rev Latino-Am Enfermagem. 2018;26:e3014. doi: https:// doi.org/10.1590/1518-8345.2257.3014

14. Günes ÜY, Gürlek Ö, Sönmez M. A survey of the patient safety culture of hospital nurses in Turkey. Collegian. 2016;23(2):225-32. doi: https://doi.org/10.1016/j. colegn.2015.02.005 
15. Campione J, Famolaro T. Promising practices for improving hospital patient safety culture. Jt Comm J Qual Patient Saf. 2018;44(1):23-32. doi: https://doi. org/10.1016/j.jcjq.2017.09.001

16. Najjar S, Baillien E, Vanhaecht $K$, Hamdan M, Euwema M, Vleugels A, et al. Similarities and differences in the associations between patient safety culture dimensions and self-reported outcomes in two different cultural settings: a national cross-sectional study in Palestinian and Belgian hospitals. BMJ Open. 2018;8:e021504. doi: https://doi.org/10.1136/bmjopen-2018-021504

17. Andrade LEL, Lopes JM, Souza Filho MCM, Vieira Júnior RF, Farias LPC, Santos CCM et al. Patient safety culture in three Brazilian hospitals with different types of management. Ciênc Saúde Coletiva. 2018;23(1):161-72. doi: https:// doi.org/10.1590/1413-81232018231.24392015
18. Okuyama JHH, Galvão TF, Silva MT. Healthcare professional's perception of patient safety measured by the hospital survey on patient safety culture: a systematic review and meta-analysis. ScientificWorldJournal. 2018;2018:915 6301. doi: https://doi.org/10.1155/2018/9156301

19. Fassarella CS, Camerini FG, Henrique DM, Almeida LF, Figueiredo MCB. Evaluation of patient safety culture: comparative study in university hospitals. Rev Esc Enferm USP. 2018;52:e03379. doi: https://doi.org/10.1590/S1980-22 OX2017033803379

20. Silveira M, Camponogara S, Beck CLC, Costa VZ, Dalmolin GL, Arboit EL. Night work and its meanings for intensive care unit nursing. Rev Enferm UERJ. 2016;24(6):e17416. doi: https://doi.org/10.12957/reuerj.2016.17416
- Corresponding author:

Alexandre Pazetto Balsanelli

E-mail: alexandre.balsanelli@unifesp.br
Email: Received: 08.29.2019

Approved: 05.28.2020

\section{Associate editor:}

Graziella Badin Aliti

\section{Editor-in-chief:}

Maria da Graça Oliveira Crossetti 